\title{
MEMBRANE SPECIALIZATIONS IN THE FORM OF REGULAR MEMBRANE-TO-MEMBRANE ATTACHMENT SITES IN PARAMECIUM. A CORRELATED FREEZE-ETCHING AND ULTRATHIN-SECTIONING ANALYSIS
}

\author{
H. PLAT'TNER, F. MILLER \\ Department of Cell Biology, University of Munich, D-8 Munich 2, Goethestrasse 33, \\ Germany
}

AND L. BACHMANN

Institute of Technical Chemistry, Technical University of Munich, D-8 Munich 2, Arcisstrasse 2 I, Germany

\begin{abstract}
S U M M A R Y
The outer membrane complex of Paramecium was investigated by ultrathin-sectioning techniques and by freeze-etching of unfixed cells without cryoprotectants. Granules were found in the freeze-etched cortical membrane complex in a highly ordered arrangement; morphometric analyses and partial disruption of this membrane complex showed that some of these granular membrane specializations (which we call types $a, b, e, f, g$ ) represent membrane-tomembrane attachment sites. Type $a$ : granules arranged in rings (single or double), $300 \mathrm{~nm}$ in diameter, connect plasmalemma and alveolar membranes around trichocysts. Type $b$ : within these $a$-type rings, a concentric zone ( $80 \mathrm{~nm}$ diameter) of granules connects plasma membrane and trichocyst membrane. Type $c$ : the trichocyst membrane further contains a central ring or patch, $80 \mathrm{~nm}$ in diameter, of rather large granules where it is in contact with the crystalline trichocyst matrix. Type $d$ : 'ciliary necklaces' are formed by groups of triple rows of $3-6$, most frequently 5 granules, with 2 I $-\mathrm{nm}$ periodicity. Rows of granules also connect the alveolar membranes to the apical portion of the trichocyst membrane (type $e$ ) and the alveolar membrane to the plasmalemma around cilia (type $f$ ). Type $g$ : the inner alveolar membrane displays an intense granularity and contains double rows of granules along alveolar septa at attachment sites between 2 alveolar membranes. Upon experimental discharge of the majority of trichocysts only the innermost concentric circles of membrane-bound granules of this region $(b-$ and $c$-type) disappeared from the plasmalemma, while the outermost $a$-type rings of granules persisted for a longer time. Among other possible functions, these regular membrane-to-membrane attachments are likely to maintain the specific cellular shape.
\end{abstract}

\section{INTRODUCTION}

During recent investigations on cryofixation (Bachmann, Schmitt \& Plattner, 1972) we observed regularly arranged granules on the plasmalemma of Paramecium. In this paper we correlate these membrane specializations with observations on ultrathin sections and describe experiments aimed at elucidating some functional aspects by partial disruption of this membrane complex.

\section{MATERIALS AND METHODS}

Cultures of Paramecium aurelia, mating type VIII, killer factor negative, were kept as suspensions at $20^{\circ} \mathrm{C}$ in a salad medium with Aerobacter aerogenes added. 
Freeze etching was generally performed on unfixed cells without the use of antifreeze agents. For comparison a few aliquots were treated with glycerol or dimethylsulphoxide. The cultures were concentrated by centrifugation and passage through Millipore ${ }^{(\mathbf{B})}$ filters (Plattner, Schmitt \& Bachmann, 1973). Most specimens were 'standard frozen' by dipping the pellets on specimen mounts in Freon 12 (melting point $-15^{\circ} \mathrm{C}$ ). As a control aliquots were 'spray frozen' (Bachmann \& Schmitt, I97I; Plattner, Fischer, Schmitt \& Bachmann, 1972) by injecting the untreated cells into liquid propane $\left(-190^{\circ} \mathrm{C}\right)$ through an electron-microscope aperture with an opening of $50 \mu \mathrm{m}$, which is slightly larger than the maximum diameter of the cells. Controls by light microscopy showed that this procedure did not damage the rather large and fragile cells (diameter $30-40 \mu \mathrm{m}$, length $120-150 \mu \mathrm{m}$ ). For details of the procedure see Bachmann et al. (1972) and Plattner et al. (1973). For freeze etching a Balzers apparatus (BA $360 \mathrm{M}$ ) was used; samples were etched at $-100^{\circ} \mathrm{C}$, routinely for I min, for deep etching up to Io min.

Ultrathin sections were obtained from normal and experimentally changed aliquots fixed in (a) $6.25 \%$ glutaraldehyde ( $\mathrm{I} \mathrm{h}$ ) followed by $\mathrm{I} \% \mathrm{OsO}_{4}(\mathrm{I} \mathrm{h})$, both in $\mathrm{O}^{\mathrm{I}} \mathrm{M}$ cacodylate buffer, $\mathrm{pH} 7 \cdot 2$; (b) a potassium dichromate- $\mathrm{OsO}_{4}$ fixative $(\mathrm{I} \mathrm{h}$ ) at $\mathrm{pH} 7 \cdot 2$ (Dalton, 1955; WohlfarthBottermann, I957); (c) a $3 \%$ acrolein-I \% potassium dichromate fixative with $6 \%$ sucrose (30 min), followed by $\mathrm{I} h$ in $20 \%$ acrolein, both adjusted to $\mathrm{pH} 7 \cdot 2$ (Robison \& Lipton, 1969). All samples were embedded in Epon (Luft, I961). Sections from specimens fixed according to methods $(a)$ and $(b)$ were stained for $20 \mathrm{~min}$ with $2 \%$ aqueous solution of magnesium uranyl acetate (British Drug Houses), followed by alkaline lead citrate (Venable \& Coggeshall, 1965). Sections from acrolein-fixed pellets were stained for $3 \mathrm{~h}$ with $2 \%$ aqueous uranyl acetate followed by lead citrate; this procedure reveals the membranes in 'negative contrast'.

Partial disruption of the superficial membrane complex was achieved by gassing cultures for $5 \mathrm{~min}$ with carbon dioxide and leaving them in this atmosphere for $30-45 \mathrm{~min}$. Discharge of trichocysts could be provoked most effectively by exposing the cultures in a closed chamber to osmium tetroxide vapour for $10-20 \mathrm{~min}$.

Each of the preparative steps was monitored in a phase-contrast microscope under oil immersion after immobilizing the cells by stirring them into an excess of methylcellulose (Methocel $^{(\mathrm{R})} \mathrm{MC}$, article 64620 , Fluka, Switzerland) diluted to appropriate viscosity. This procedure had no visible influence on the cells.

Measurements of the sizes of structures were carried out on prints with a final magnification of 50000 times or more; freeze-fractured and cross-cut circular structures were measured in 2 perpendicular axes.

\section{RESULTS}

\section{Gross surface pattern}

With the spray-freezing method it was possible to achieve an acceptable quality of cryofixation of a considerable fraction of paramecium cells (Fig. 3); 'standard' freezing of untreated cells results in heavy ice damage in the cytoplasm (Bachmann et al. 1972; Plattner et al. 1973). Although the interior of the cells is preserved far better after spray-freezing, the regularly arranged granular patterns described in this paper were detected after both freezing methods; therefore we are confident that they represent true local membrane differentiation zones and not mere artifacts.*

Fracture planes tangential to the body surface display a regular pattern (Figs. $6,7)$ which can be closely correlated with ultrathin sections in the same plane (Figs.

- A common procedure in current use for freeze etching is to fix samples in glutaraldehyde and to incubate them in an antifreeze agent, mostly in glycerol. Such a fixation, however, does not stabilize membrane lipids, and according to X-ray diffraction (Moretz, Akers \& Parsons, I 969) and circular dichroism studies (Lenard \& Singer, r968) the structure of membrane proteins is considerably disturbed even by brief fixation in glutaraldehyde. All micrographs of replicas presented in this paper were obtained without prefixation and without treatment with antifreeze agents. 
$4,5)$. The body surface is subdivided into concave squares arranged on longitudinal bands; the periods of adjacent bands are frequently displaced relative to each other (e.g. by half a period). Cilia always emerge from the bottom of the squares. In grazing ultrathin sections trichocyst tips alternate with cilia along longitudinal lines; they abut on to cytoplasmic ridges which delimit each surface square. It is precisely at those attachment sites of trichocysts where replicas exhibit rings of granules within the plasmalemma. This situation is summarized in Fig. I.

Underneath the plasmalemma the membrane system of the alveolar cavity is located; this cavity extends between 2 lines of trichocysts and cilia. From negative staining (Hufnagel, I969) and occasional freeze-etching observations (Fig. 7) one can

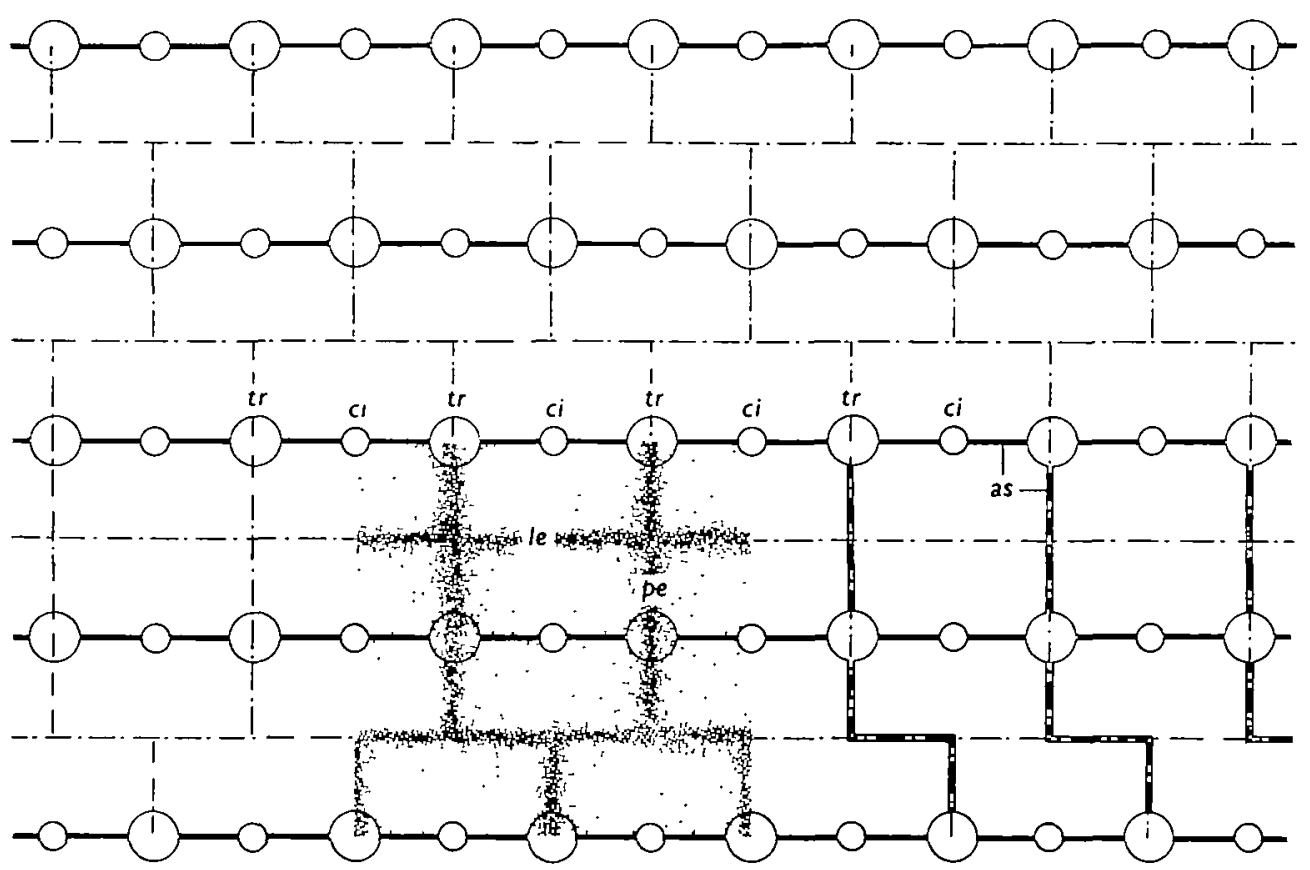

Fig. I. Schematic view of the surface of a Paramecium cell; to be compared with Figs. $4-6$. Trichocysts $(t r)$ and cilia $(c i)$ are alternately arranged in regular intervals along parallel lines. The periods of adjacent longitudinal lines are frequently displaced, e.g. by half a period. Alveolar cavities extend between 2 longitudinal lines of trichocysts and cilia; alveolar membranes are closely attached to each other along the alveolar septa, as (compare Fig. 5). According to negative-staining results (Hufnagel, 1969) and occasional freeze-etching observations (Fig. 7) it appears likely that the alveolar cavities might be subdivided also in perpendicular direction to form square cushion-like elements; this situation is represented in the bottom right area. Where parallel periods are displaced with regard to each other, the alveolar sacs are no longer square-shaped but they might follow this displacement. The dotted zones indicate the curvature of the surface relief which exhibits the same periodicity but is superposed with a lateral displacement of half a period: thus cilia always protrude from the depressions, whereas trichocysts always come to abut on the perpendicular elevations ( $p e$ ) of the body surface. le, longitudinal elevations of this surface relief. The scheme does not show that occasionally trichocysts might be missing or out of line; cilia might be absent or present in pairs; alveoli might be absent at some sites (e.g. around the cytostome; Pitelka, 1965). 
690

assume that the alveolar cavity can be subdivided also in the perpendicular direction; thus the alveolar sacs form cushion-like squares with the trichocyst tips at their corners. However, it is not certain whether the alveolar cavity is subdivided in this perpendicular direction in all regions of the body surface (see also Allen, 1971). When the periods of neighbouring bands of squares are displaced, the edges of the alveolar sacs no longer form squares but follow this displacement (see Figs. I, 7).

\section{Membrane specializations under normal conditions}

In views from outside the cells, freeze-etching replicas exhibit regular rings of membrane-bound granules precisely at those sites of the body surface pattern that coincide with the occurrence of trichocyst tips as seen in grazing ultrathin sections (Figs. 2, 4-13). Similar but less-conspicuous rings of granules or holes can be seen from inside the cell (Figs. 2, II). In views from outside the cell (Figs. 6, 8-IO) they consist of $(a)$ an outermost single or double ' $a$-type ring', $300 \mathrm{~nm}$ in diameter; $(b)$ a concentric middle ring or a diffuse zone of granules, $180 \mathrm{~nm}$ in diameter, and finally (c) a central patch, $80 \mathrm{~nm}$ in diameter, of rather large granules or corresponding holes. Apart from the geometric arrangement, the correlation of $a-, b$ - and $c$-type rings with the underlying trichocyst tips is further supported by occasional observations of beginning exocytosis of trichocysts in these regions (Fig. 13). In those parts of the replica which were exposed by deep etching, these structures are not visible (Fig. 8) beyond the 'ridge' (compare Branton, 197I) limiting frequently fracturing planes (see Discussion). This indicates that they are located within the plasma membrane.

On ultrathin sections parallel to the cortical region, this particular plane through the uppermost trichocyst tip was encountered very rarely; it appears, though, from Fig. 12 that ring-like structures of similar size, containing electron-dense subunits, occur also in these preparations.

Median sections through trichocysts were more frequent and allowed a quantitative comparison of dimensions with those in freeze-etching replicas (Table $\mathbf{I}$; to be compared with Fig. 2). The outer portion of the alveolar membrane lies underneath and close to the continuous sheath of the plasmalemma; the alveolar membrane is folded

Fig. 2. This schematic cross-section through the surface-membrane complex indicates the sites of membrane specializations $(a-g)$ seen on micrographs from freeze-etching replicas. al, alveolus; as, alveolar septum; $c i$, cilium; $c t m$, crystalline trichocyst matrix; $p m$, plasma membrane; $p s$, parasomal sac; $t r$, trichocyst. The plasmalemma is connected (a) to the alveolar membrane by single or double, $300-\mathrm{nm} a$-type rings of granules, and (b) to the trichocyst membrane by an inner concentric circle $180 \mathrm{~nm}$ in diameter ( $b$-type granules). The membrane of the trichocyst tip contains a patch (diameter $80 \mathrm{~nm}$ ) of somewhat larger granules $(c)$. On its basal portion the ciliary membrane displays groups of triple rows of granules $(d)$ with a periodicity (longitudinal to the ciliary shaft) of $d^{\prime}=2 \mathrm{I} \mathrm{nm}$. The trichocyst membrane is also connected (e) with the alveolar membrane (e-type granules). The inner portions of the alveolar membrane exhibit a granular appearance; they are connected to each other at the alveolar septa (as) by a suture formed by a double row of granules $(\mathrm{g})$. It is not certain whether similar attachment sites occur also at the outer side of the alveolar septum. Around cilia $(f)$ the alveolar membrane is attached to the plasmalemma by an irregular ring of $f$-type granules. Electron micrographs, $\times 56000$. 

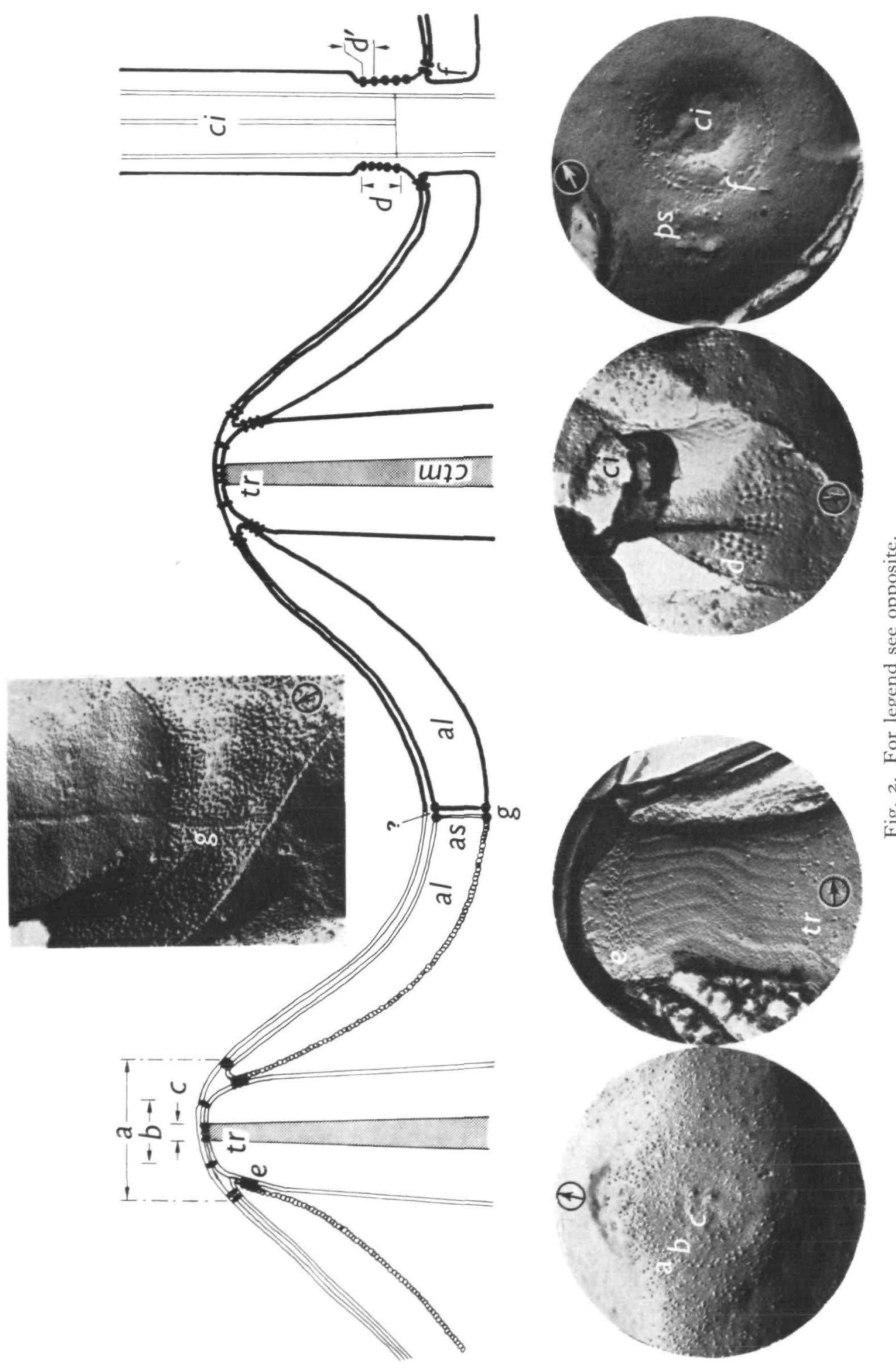
692

back in a downwards direction to form the inner alveolar membrane as it approaches the trichocyst tip. The dimensions of the outermost ( $a$-type) ring in replicas (280$300 \mathrm{~nm} \pm 40$ ) coincide with the border of the alveoli $(300 \mathrm{~nm} \pm 40)$; frequently a somewhat diffuse electron-dense zone is located there between plasmalemma and the rim of the alveolar membranes as seen on median sections through trichocysts (Figs. 16, 17). Another, 140-nm \pm 30 broad diffuse dense zone is found on the trichocyst tip and correlates with the $180-\mathrm{nm} \pm 40$ wide $b$-type granular membrane structures of

Table I. Quantitative evaluation of membrane specializations

\begin{tabular}{|c|c|c|c|c|}
\hline \multirow{3}{*}{$\frac{\text { Structure }}{a}$} & \multicolumn{4}{|c|}{ Preparation procedure } \\
\hline & \multicolumn{2}{|c|}{ Freeze-etching replicas } & \multicolumn{2}{|c|}{ Ultrathin sections } \\
\hline & $\begin{array}{l}280 \pm 40(57) \\
300 \pm 40(50)\end{array}$ & $\begin{array}{l}\text { Outside view } \\
\text { Inside view }\end{array}$ & $300 \pm 40(16)$ & Longitudinal sections \\
\hline$b$ & $180 \pm 40(33)$ & Outside view & $140 \pm 30(17)$ & Longitudinal sections \\
\hline$c$ & $80 \pm$ I $5(38)$ & Inside view & $70 \pm 18(20)$ & Cross-sections \\
\hline $\begin{array}{l}d \\
d^{\prime}\end{array}$ & $\begin{array}{l}97 \pm 24(18) \\
21 \pm 2 \cdot 5(17)\end{array}$ & $\left.\begin{array}{l}\text { Outside view } \\
\text { Outside view }\end{array}\right\}$ & correlates not & sible \\
\hline
\end{tabular}

Values are stated in $\mathrm{nm} \pm$ S.D., with numbers of structures counted in parentheses. $a-c$ refer to the regions where trichocysts are located (see Fig. 2): $a$, plasma membrane-outer alveolar membrane attachment; $b$, middle ring (trichocyst membrane-plasma membrane attachment); $c$, innermost ring or patch of granules (located on top of the trichocyst centre); $d$, length of ciliary necklace; $d^{\prime}$ indicates the period of granules in this structure along the ciliary axis.

replicas (Figs. 2, 9, I0). The innermost $c$-type granules form an 80-nm \pm 15 broad patch and must necessarily be located above the crystalline matrix of the trichocysts. Since these rather large $c$-type granules are seen only occasionally on fracture views from outside the cell, but regularly from inside (Figs. 7, II), it is not clear whether they penetrate beyond the trichocyst tip into the plasmalemma. Both $a$ - and $c$-type structures present themselves alternatively either as granules or holes; hence it can be excluded that they are due to specifically arranged contaminants. We also agree with Bannister (1972) that the fibrogranular layer (Pitelka, 1965) is restricted to the region underneath the inner alveolar membrane and does not extend beyond the contact zone between the trichocyst tip and the plasmalemma.

Further membrane specializations (Fig. 2) were found in the freeze-etched plasmalemma at the bases of cilia. Triple rows of three to six - most frequently $(50 \%$ of observations) five-granules, reminiscent of the 'ciliary necklace' discovered by Flower (1971) and Gilula \& Satir (1972) on a variety of cilia, and here termed $d$-type granules, were spaced with a periodicity of $21 \mathrm{~nm} \pm 2.5$ along the ciliary shaft. At the contact sites between alveolar membrane and trichocyst membrane, freezeetching replicas display rings (e-type) of densely packed granules (Fig. 2, e). Where the alveolar membrane surrounds the cilia (Fig. 2, $f$ ), the plasmalemma contains similar granular rings. No conspicuous membrane specializations were seen at the sites of parasomal sacs (Fig. 2). The alveolar septa resulting from the close contact of membranes from adjacent alveolar cavities display along their bases a 
double row of granules (Fig. 2). Fracture faces of the inner portion of the alveolar membrane always exhibited a coarse appearance of densely packed granular substructures (Figs. 2, 2I), unlike the fracture faces of the other biomembranes; the surfaces exposed by etching were essentially smooth.

\section{Experiments on partial disruption of the cortical membrane complex}

We tried to elucidate some functional aspects of the regular membrane specializations mentioned above. Spontaneous exocytosis of trichocysts was rather rare. When spontaneous exocytosis of trichocysts was occasionally observed on replicas (Fig. 13) the $a$-type rings remained unchanged and the membrane regions outside and within the rings appeared unaltered, as the trichocyst tip started to penetrate the plasmalemma. At exocytosis sites seen in ultrathin sections of fixed normal cells a continuous transition between plasmalemma and trichocyst membrane appears (Fig. 22). Similarly, when biomembranes are visualized in negative contrast using high acrolein concentrations and appropriate section staining (see Methods), close contact between both membranes becomes evident (Fig. I8).

After a variety of attempts we achieved the most reliable discharge of the majority of trichocysts in a major fraction of the cell population by exposing them to osmium tetroxide vapour (Figs. 15, 2I). Similar but less effective results were obtained when cells were treated with $10 \%$ dimethylsulphoxide. The discharge of trichocysts was monitored by phase-contrast microscopy and then by electron microscopy of ultrathin sections (Fig. 15) and of replicas (Fig. 21). Upon massive discharge of trichocysts the following observations were made on the plasma membrane after freeze etching: occasional holes, $0.2-0.25 \mu \mathrm{m}$ in diameter, occur (Fig. 23); $b$ - and $c$-type particles frequently vanish (Fig. 24), whereas $a$-type rings persist as during spontaneous exocytosis, though they seem to decompose later on. Despite the high effectiveness of exocytosis triggering, the number of open holes seen in the freeze-etched plasmalemma was strikingly small; both ultrathin sections (Fig. I 5) and replicas (Figs. 23, 24) reveal that plasmalemma and trichocyst membranes become closed again after discharge. The sudden disappearance of both $b$ - and $c$-type granules is further indication of a certain mobility of membrane constituents in the regions active in exocytosis. However, we were unable to observe in our system membrane changes similar to those ascribed by Satir, Schooley \& Satir (1972, 1973) to spontaneous exocytosis in Tetrahymena.

After massive ejection of trichocysts the cortical membrane complex as a whole first persists but then proceeds to disintegrate; this situation becomes fatal to the animals. Similar disruptions are observed regularly when cells are exposed to a carbon dioxide atmosphere (which, however, does not provoke trichocyst discharge). In these cases ultrathin sections clearly exhibit regularly distributed (Figs. 15, 19, 20) membrane fragments at the following sites on the body surface: (1) remnants of plasmalemma attached to the alveolar membrane; (2) fragments attached to the trichocyst tip; (3) alveolar membranes attached to the trichocyst tip; (4) pieces of plasmalemma and outer alveolar membrane persisting around the ciliary bases; (5) remnants of the membranes of 2 contiguous alveoli (though detached from the trichocyst sites) still 
694

remain attached to each other along the alveolar septa (Fig. 19). All this evidence suggests that $a-, b-, e-, f$ - and $g$-types of granular membrane specializations represent membrane-to-membrane attachment sites. Only $b$ - and $c$-type structures on the trichocyst tips largely disappear in replicas after exocytosis and thus might be directly related to this process.

After massive experimental disruption of the superficial membrane complex the cytoplasm finally remained covered by the inner alveolar membrane, the fractures of which display a highly granular aspect (as they do in normal cells). As a consequence, large areas of the cell body lose their surface relief (Figs. 22, 23) and the cell becomes round.

\section{DISCUSSION}

Restrictions imposed by the method on the interpretation of the freeze-etching results

Before discussing the results we should like to comment on potential artifacts of freeze etching related to this study. The question could be raised whether and to what extent the described structures are influenced by insufficient cryofixation (segregation artifacts: Schmitt, Zingsheim \& Bachmann, 1970; Dunlop \& Robards, 1972; Plattner et al. 1972); by plastic deformations during cleaving (Clark \& Branton, I 968; Schmitt et al. 1970; Dunlop \& Robards, 1972) or finally by contamination during etching (Davy \& Branton, 1970; Moor, 1971; Staehelin \& Bertaud, 197I). As already mentioned, identical surface structures of the membrane were observed after 'standard' freezing and after spray-freezing. In previous papers it has been shown that segregation artifacts caused by the relatively slow cooling rates during standard freezing are greatly reduced by spray-freezing (Bachmann $\&$ Schmitt, I97I; Plattner et al. 1972). The identical appearance of the granular membrane specializations after the use of $z$ different freezing methods therefore speaks for the absence of segregation artifacts in this particular case. As no fixation or cryoprotective agents have been used, corresponding artifacts must also be excluded.

Cleaving artifacts can be excluded on the basis of Figs. 9-II: when viewed from the outside of the cell, the inner half of the plasma membrane shows rows of particles; when viewed from the inside of the cell, the same structures appear on the outer half of the plasma membrane as depressions. The same argument of the matching fracture patterns excludes their interpretation as contaminations.

\section{Interpretation of membrane substructure in Paramecium}

Paramecia offer several advantages for the study of biomembrane ultrastructure: first, the regular geometrical arrangement of cortical organelles (cilia, trichocysts); secondly, the correlation of membrane specializations - as observed by freeze etching with these organelles; thirdly, the accessibility of these surface-bound structures to experimental manipulations such as discharge of trichocysts; fourthly, the geometrical pattern greatly facilitates the localization of experimentally changed membrane regions. The chance to study experimentally induced exocytosis is offered by the presence of trichocysts.

Based on ultrathin-sectioning techniques, the normal ultrastructure of Paramecium 
aurelia was summarized by Jurand \& Selman (1969). Important ultrastructural information on the cortical region was given by Pitelka (1965) and Allen (197I) ( $P$. caudatum), using ultrathin-sectioning techniques, and by Hufnagel (1969) by means of negative staining. Trichocyst morphology was recently described in detail by Bannister (1972). However, membrane specializations described in this paper could be revealed only by freeze-etching. Among them, the most prominent features are $a$-type rings of granules in the plasmalemma, which were simultaneously reported by Bachmann et al. (1972) and by Janisch (1972).

These ring-like structures were not visible on the cell surface exposed by deepetching experiments. The fracture plane must be located within an internal plane of the plasmalemma because rings of granules (or holes) are recognized on fractures, whether viewed from inside or outside the cell; this means that both split halves match. However, the ridge on the surface of all etched preparations was persistently very thick and could not be accounted for by only one half of a split lipid bilayer. As mentioned above, spray-freeze etching reduces the apposition of dissolved materials on to surfaces. Since the ridge is equally thick after spray freezing and after standard freezing, the ridge material must represent a constituent of the plasmalemma. This agrees with Fig. I7, which shows the occurrence of an amorphous surface coat whose dimensions could account for the rather thick outer stratum of the ridge; in fact, the replicated ridge appears subdivided by a middle line (Fig. 8). Following Branton's membrane splitting theory (Branton, 1971), we would conclude that the granules are located within the bilayer structure of the plasmalemma. Freeze-substitution studies by Hereward \& Northcote (1972) on fractured yeast cells show that this assumption is not necessarily valid for other biomembranes.

Measurements of the dimensions of membrane specializations uncovered by freezeetching exhibited a close correlation with several structural dimensions of the cortical membrane complex in ultrathin sections. Partial disruption could be achieved in a rather unspecific but most effective way by exposing the cultures to a carbon dioxide atmosphere; large portions of the plasmalemma and of the outer alveolar membrane are then removed. However, bits of membrane fragments were regularly found attached at 3 sites: around the trichocyst tip; around the bases of cilia; and at the alveolar septa. Thus, one can conclude that the plasmalemma is attached to the alveolar membrane around the trichocysts ( $a$-type rings) and around cilia ( $f$-type rings); the plasmalemma is also fixed to the trichocyst membrane ( $b$-type rings); the trichocyst membrane is also connected to the alveolar membrane (e-type); at least one attachment line proceeds along the alveolar septa ( $g$-type). Unfortunately we could not obtain large fracture areas along the outer alveolar membrane; Wunderlich \& Speth (1972) found a similar 'suture' on the outer alveolar sheath of Tetrahymena; therefore, an analogous situation can be expected for paramecia. Since Nozawa \& Thompson (197I) were able to isolate this cortical membrane complex as a whole (including: plasma membrane, alveolar membranes, trichocysts and cilia) from Tetrahymena pyriformis, further proof for the existence of membrane-to-membrane attachments in Paramecium could probably be provided by similar sub-fractionation studies. 
696

Irrespective of the method by which the cortical membrane complex is broken down to the inner portion of the alveolar membrane, the animals lose their specific body shape and become round; it can therefore be concluded that the attachment sites between the individual strata play a role in maintaining the familiar slipper shape.

Besides the well defined granular patterns at membrane-to-membrane attachment sites, most fracture faces of membranes appeared rather smooth and contained only a few irregularly distributed particles. Only the inner alveolar membrane always presented a very coarse granular pattern, both in normal cells and in cells exposed to an osmium tetroxide or carbon dioxide atmosphere. Similar coarse fracture patterns were observed on the inner alveolar membrane of Tetrahymena (Wunderlich \& Speth, I972) and on the inner portion of the acrosomal membrane of bovine spermatozoa (Plattner, 1971).

Another specialized region of the plasmalemma was found in form of regular triple rows of granules at the ciliary bases (Fig. 2, d). This structure might correspond to the ciliary necklace described by Flower (1971) and Gilula \& Satir (1972) on cilia of different origin, although the structure found in Paramecium is somewhat different and resembles most closely its analogue in Tetrahymena (Wunderlich \& Speth, 1972).

The cortical membrane complex of paramecia could also be manipulated by stimulating the ejection of trichocysts. To study this process an effective discharge of the major fraction of these organelles within a majority of the whole cell population (Fig. I5) is necessary, because spontaneous exocytosis occurs rather rarely. If this prerequisite is not established the following difficulties with the interpretation of static pictures arise: the membrane specializations seen within the zone of close connexion between the trichocyst tip and the plasma membrane are somewhat variable; the middle granular zone (b-type) can form either a well defined ring or a diffuse patchy zone of granules or it can be absent. The innermost narrow patch of larger $c$-type granules, which is seen rather regularly on views from inside the cell, can be seen from the outside only where the innermost portion of the trichocyst tip protrudes to form a 'bump' on the body surface; we assume that in this situation, remnants of the lower half of the plasmalemma are fractured away in this very narrow, ill-defined zone. All this leads to a variety of possible morphological aspects within the extrusion zone of trichocysts in normal cells.

During and immediately after exocytosis, the $b$ - and $c$-type granules disappear (Fig. 24), whereas the a-type rings persist until the cortical membrane complex decays as a consequence of massive, lethal trichocyst discharge (Fig. 23). The granular patterns observed by Satir et al. (1972, 1973) during spontaneous exocytosis of trichocysts in Tetrahymena were not found in Paramecium.

Water influx and osmotically provoked expansion was proposed for propulsion of exocytosis (see Satir et al. 1972, 1973). Though exposing cells to osmium tetroxide vapour is not a physiological way to stimulate exocytosis, various stimuli might act on a similar basis. Both dimethylsulphoxide (see also Hausmann, Stockem \& Wohlfarth-Bottermann, 1972) and osmium tetroxide vapour were found in the present study to provoke a massive trichocyst expulsion; both DMSO (Misch \& Misch, I967; Gerhards \& Gibian, 1968; Graham \& Pace, I968; Pribor \& Nara, 1969) and $\mathrm{OsO}_{4}$ 
(Elbers, 1966; Bone \& Denton, I97I; Busson-Mabillot, I97I; Morel, Baker \& Wayland, 197I) are also known to enhance membrane permeability. Fixation by osmium tetroxide solutions did not cause trichocyst discharge. Short treatment with osmium tetroxide vapour evidently does not lead immediately to sufficient fixation, but allows the cells to react by trichocyst emission. Neither was a decrease of membrane-oriented fracture planes observed in this case, as introduced by fixation with $\mathrm{OsO}_{4}$ solutions (James \& Branton, $\mathrm{r}$ 97 I). Although there are some differences with regard to morphological details in Tetrahymena and Paramecium, the mechanism of exocytosis proposed by Satir and co-workers might as well operate in Paramecium; trichocysts could be discharged after a sudden change in membrane permeability.

As shown by Bannister ( 1972 ), the crystalline matrix of the trichocyst tip contains a set of microtubules; possibly these are connected with some of the granular specializations of the tip membrane and might participate in the exocytotic process. The longitudinal impressions seen on the outside of the trichocyst-neck membrane (Fig. 2) terminate at the $e$-type ring and reflect the close apposition of an outer microtubule sheath.

The present study conclusively demonstrates the occurrence of granular membraneto-membrane attachment sites within the cortical membrane complex of a single cell. It may be noted that electron-dense dots have also been found between adjacent intracellular membranes on ultrathin sections of various cells and interpreted as crossbridges (Franke et al. 1971). No data on the chemical nature of the particles exposed by freeze etching in the cortical membrane complex are available. Further experiments are necessary to establish the connexion between some of the membrane specializations and their possible function in exocytosis. Some of the membrane-to-membrane attachments might also act as a linking site to avoid open contact between cytoplasm and ambient medium during exocytosis; indeed, a direct transition of the plasma membrane and the trichocyst 'ghost' membrane was observed during spontaneous exocytosis. Many of the junction-like membrane specializations are encountered in the plasmalemma just at those sites where the compartments of trichocysts and alveoli are closely apposed; hence these attachment sites might act as pericellular junctions; indeed, according to observations by ourselves and Pitelka (1965), the alveolar sacs can be seen on ultrathin sections in very different, expanded or collapsed states, depending on the osmotic conditions during fixation. Besides these possibilities it is suggested that some of the membrane-to-membrane attachiment sites act as 'rivets' in maintaining the specific cell shape.

We gratefully acknowledge the technical assistance of Mrs A. Gansmüller-Bernier, Miss M. Einkemmer, Mrs R. Gebhardt, Mrs B. Hahn, Miss I. Steffens and Mrs H. Woschina, the help of Mrs L. Döhle in preparing the prints and of Mrs R. Mylonas in preparing the manuscript. The work was supported by the Deutsche Forschungsgemeinschaft. 


\section{REFERENCES}

AlleN, R. D. (197I). Fine structure of membranous and microfibrillar systems in the cortex of Paramecium caudatum. Y. Cell Biol. 49, 1-20.

BachmanN, L. \& Schmit, W. W. (I97I). Improved cryofixation applicable to freeze etching. Proc. natn. Acad. Sci. U.S.A. 68, 2149-2152.

BachmanN, L., Schmitt, W. W. \& Plattrer, H. (1972). Improved cryofixation: Demonstrated on freeze-etched solutions, cell fractions and unicellular organisms. Proc. $5^{\text {th }}$ Europ. reg. Congr. Electron Microsc. (ed. V. E. Coslett), pp. 244-245. London, Bristol: The Institute of Physics.

BAnnister, L. H. (1972). The structure of trichocysts in Paramecium caudatumi. F. Cell Sci. II, 899-929.

Bone, Q. \& Denton, E. J. (197I). The osmotic effects of electron microscope fixatives. F. Cell Biol. 49, 571-58I.

Branton, D. (I97I). Freeze-etching studies of membrane structure. Phil. Trans. R. Soc. Ser. $B$ 26r, I33-1 38 .

Busson-Mabillot, S. (197I). Influence de la fixation chimique sur les ultrastructures. I. Etude sur les organites du follicule ovarien d'un poisson téléostéen. \%. Microscopie r2, 317-348.

Clark, A. W. \& Branton, D. (I 968). Fracture faces in frozen outer segments from the guinea pig retina. Z. Zellforsch. mikrosk. Anat. 9r, 586-603.

Dalton, A. J. (1955). A chrome-osmium fixative for electron microscopy. Anat. Rec. 121, 281.

Davy, J. G. \& Branton, D. (1970). Subliming ice surfaces: freeze-etch electron microscopy. Science, N.Y. I68, I216-1218.

Dunlop, W. F. \& Robards, A. W. (1972). Some artifacts of the freeze-etching technique. 7. Ultrastruct. Res. 40, 391-400.

ElgERS, P. F. (1966). Ion permeability of the egg of Limnea stagnalis L. on fixation for electron microscopy. Biochim. biophys. Acta 112, 318-329.

Flower, N. E. (1971). Particles within membranes: a freeze-etch view. F. Cell Sci. 9, 435-441.

Franke, W. W., Kartenteck, J., Zentgraf, H., Scheer, U. \& Falk, H. (I97I). Membraneto-membrane cross-bridges. A means to orientation and interaction of membrane faces. 7. Cell Biol. 51, $881-888$.

GerhaRds, E. \& Gibian, H. (1968). Stoffwechsel und Wirkung des Dimethylsulfoxids. Naturwissenschaften $55,435-438$.

Gilula, N. B. \& Satir, B. (1972). The ciliary necklace. A ciliary membrane specialization. 7. Cell Biol. 53, 494-509.

Graham, E. F. \& PaCE, M. M. (1968). Some biochemical changes in spermatozoa due to freezing. Cryobiology 4, 75-84.

Hausmann, K., Stockem, W. \& Wohlfarth-Bottermann, K. E. (1972). Cytologische Studien an Trichocysten. I. Die Feinstruktur der gestreckten Spindeltrichocyste von Paramecium caudațum. Cytobiologie 5, 208-227.

Hereward, F. V. \& NorthCote, D. H. (1972). Localization of freeze-fracture planes of yeast membranes. 7. Cell Sci. 10, 555-562.

HufNagel, L. A. (1969). Cortical ultrastructure of Paramecium aurelia. Studies on isolated pellicles. 9. Cell Biol. 40, 779-801.

James, R. \& BRANTON, D. (197I). The correlation between the saturation of membrane fatty acids and the presence of membrane fracture faces after osmium fixation. Biochim. biophys. Acta 233, 504-5I2.

Janisch, R. (I972). Pellicle of Paramecium caudatum as revealed by freeze etching. F. Protozool. I9, $470-472$.

Jurand, A. \& Selman, G. G. (i 969). The Anatomy of Paramecium aurelia. London: Macmillan.

LENARD, J. \& Singer, S. J. (1968). Alteration of the conformation of proteins in red blood cell membranes and in solution by fixatives used in electron microscopy. 7 . Cell Biol. 37, I 1 7-121,

LUFT, J. H. (1961). Improvements in epoxy resin embedding methods. J. biophys. biochem. Cytol. 9, 409-414.

Misch, D. W. \& Misch, M. S. (I967). Dimethyl sulfoxide: activation of lysosomes in vitro. Proc. natn. Acad. Sci. U.S.A. 58, 2462-2467. 
Moor, H. (197I). Recent progress in the freeze-etching technique. Phil. Trans. R. Soc. Ser. B 261, I2I-I3I.

Morel, F. M. M., Baker, R. F. \& Wayland, H. (1971). Quantitation of human red blood cell fixation by glutaraldehyde. F. Cell Biol. 48, 91-100.

Moretz, R. C., Akers, C. K. \& Parsons, D. F. (1969). Use of small angle X-ray diffraction to investigate disordering of membranes during preparation for electron microscopy. Biochim. biophys. Acta 193, 12-2 I.

Nozawa, Y. \& Thompson, G. A. (I971). Studies of membrane formation in Tetrahymena pyriformis. II. Isolation and lipid analysis of cell fractions. J. Cell Biol. 49, 71 2-72 I.

Pitelka, D. R. (1965). New observations on cortical ultrastructure in Paramecium. F. Microscopie 4, 373-394.

PlattNer, H. (1971). Bull spermatozoa: A re-investigation by freeze-etching using widely different cryofixation procedures. $\mathcal{F}$. Submicrosc. Cytol. 3, 19-32.

Plattner, H., Fischer, W. M., Schmitt, W. W. \& Bachmann, L. (i 972). Freeze etching of cells without cryoprotectants. F. Cell Biol. 53, i 16-126.

Plattner, H., Schmitt, W. W. \& Bachmann, L. (1973). Cryofixation of single cells by spray freezing. In Freeze-etching (ed. E. L. Benedetti and P. Favard). Paris: Société Française de Microscopie Electronique. (In Press.)

Pribor, D. B. \& Nara, A. (1969). Toxicity and cryoprotection by dimethyl sulfoxide and by glycerol in isolated frog sciatic nerves. Cryobiology $5,355-365$.

Robison, W. G. \& Lipton, B. H. (1969). Advantages of dichromate-acrolein fixation for preservation of ultrastructural details. F. Cell Biol. 43, i i 7 a-I i 8 a.

SATIR, B., Schooley, C. \& SatiR, P. (1972). Membrane reorganization during secretion in Tetrahymena. Nature, Lond. 235, 53-54.

Satir, B., Schooley, C. \& Satir, P. (1973). Membrane fusion in a model system. Mucocyst secretion in Tetrahymena. F. Cell Biol. 56, $153-176$.

Schmitt, W. W., Zingsheim, H. P. \& BachmanN, L. (1970). Investigation of molecular and micellar solutions by freeze etching. Proc. 7th int. Conf. Electron Microsc., Grenoble, vol. I (ed. P. Favard), pp. 455-456. Paris: Société Française de Microscopie Electronique.

Staehelin, L. A. \& Bertaud, W. S. (I97 I). Temperature and contamination dependent freezeetch images of frozen water and glycerol solutions. F. Ultrastruct. Res. 37, I46-168.

Venable, J. H. \& Coggeshall, R. (1965). A simplified lead citrate stain for use in electron microscopy. 7. Cell Biol. 25, 407-4I3.

Wohlfarth-BotTermann, K. E. (I957). Die Kontrastierung tierischer Zellen und Gewebe im Rahmen ihrer elektronenmikroskopischen Untersuchung an ultradünnen Schnitten. Naturwissenschaften 44, 287-288.

Wunderlich, F. \& SPETH, V. (I972). Membranes in Tetrahymena. I. The cortical pattern. 7. Ultrastruct. Res. 41, 258-269.

(Received 3 April 1973) 


\section{ABBREVIATIONS ON PLATES}

$a$, plasma membrane-alveolar membrane attachment near trichocyst sites

$a l$, alveolus

$a m$, alveolar membrane

$a m_{i}$, inner portion of alveolar membrane

$a m_{0}$, outer portion of alveolar membrane

as, alveolar septum

$b$, plasma membrane-trichocyst membrane attachment

$c$, granules on top of trichocyst membrane

ci, cilium

ctm, crystalline trichocyst matrix

$d$, 'ciliary necklace' $e$, trichocyst membrane-alveolar membrane attachment

$f$, plasma membrane-alveolar membrane attachment near cilia

$g$, attachments (sutures) between alveolar membranes

le, longitudinal elevations of body surface relief

pe, perpendicular elevations of body surface relief

$p m$, plasma membrane

ps, parasomal sac

$t m$, trichocyst membrane

tr, trichocyst

Shadowing directions are indicated by arrows in circles.

Fig. 3. Spray-frozen, untreated Paramecium cell. The quality of cryofixation is equal throughout the cell body and the cortical membrane complex is well preserved. Several trichocysts $(t r)$ and cilia $(c i)$ are attached to the wavy body surface. $\times 7500$. 
Membrane-to-membrane attachment sites

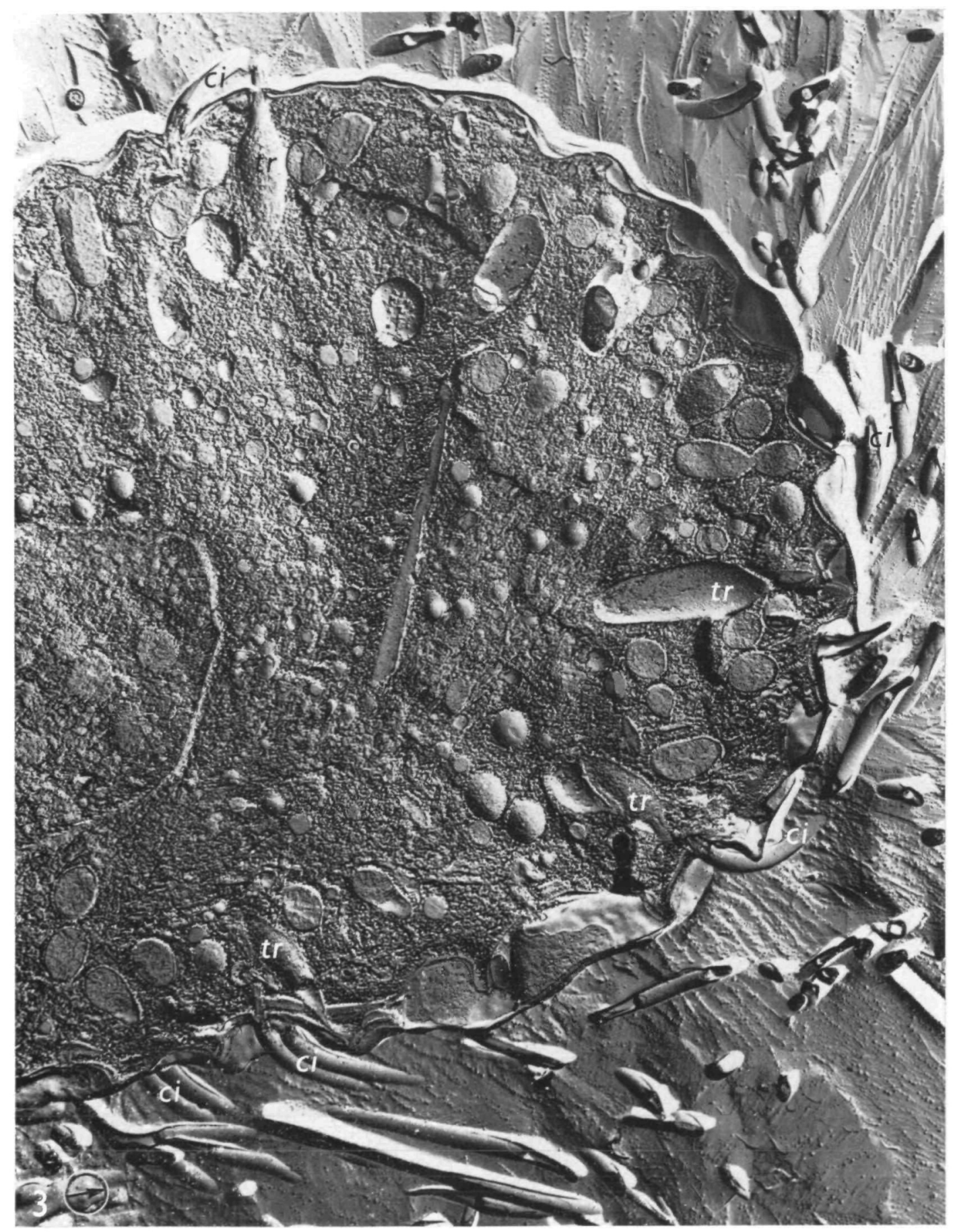


Figs. 4, 5. Tangential sections through the body surface.

Fig. 4. As depicted in the scheme of Fig. I, cilia (ci) and trichocysts (tr) are arranged in parallel lines (dashed and dotted line); the body surface is subdivided by longitudinal (le) and perpendicular ( $p e$ ) elevations into concave squares (dotted) with the cilia emerging from their bases. Trichocysts abut on to elevations perpendicular to the body axis ( $p e$ ). Alveolar cavities $(a l)$ surround each square and occasionally longitudinal alveolar septa (as) are seen close to the sites of trichocyst attachment. Closely apposed alveolar membranes (asterisk) might correspond to perpendicular alveolar septa. $\times 24000$.

Fig. 5. Same situation as in Fig. 4, but the sectioning plane lies somewhat deeper, so that the alveolar septa along the longitudinal trichocyst-cilia-axis are seen more clearly. $\times 26$ I 00 . 


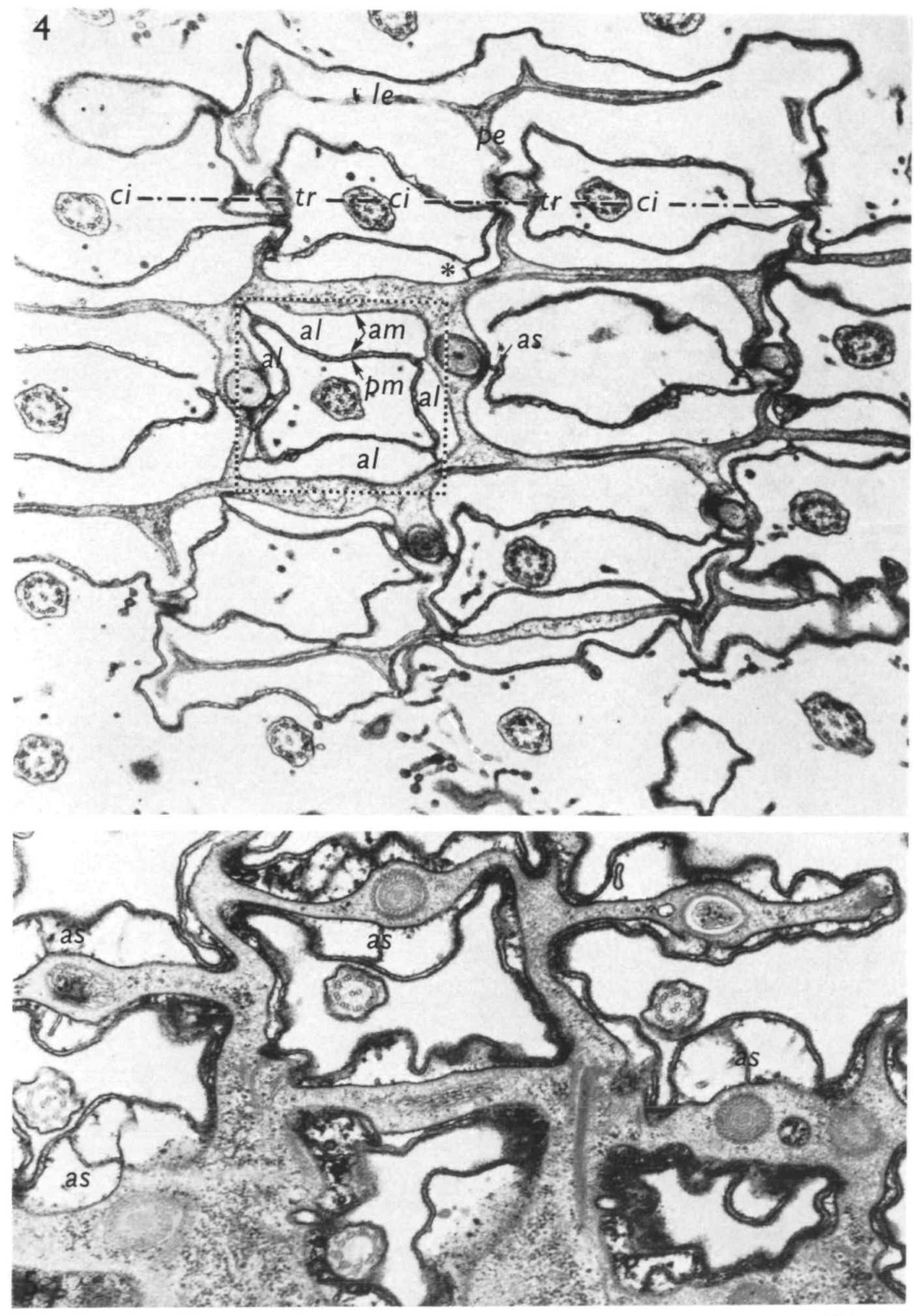


Fig. 6. Outside view of a fracture along the surface membrane. The pattern corresponds to Figs. 4 and 5 and the scheme of Fig. $I$; the fracture exposes longitudinally arranged concave squares with remnants of fractured cilia $(c i)$ at the bottom and circular membrane specializations (a) located in line with the cilia. Thus the geometrical arrangement of the rings corresponds to the distribution of trichocysts. $\times 32000$. 


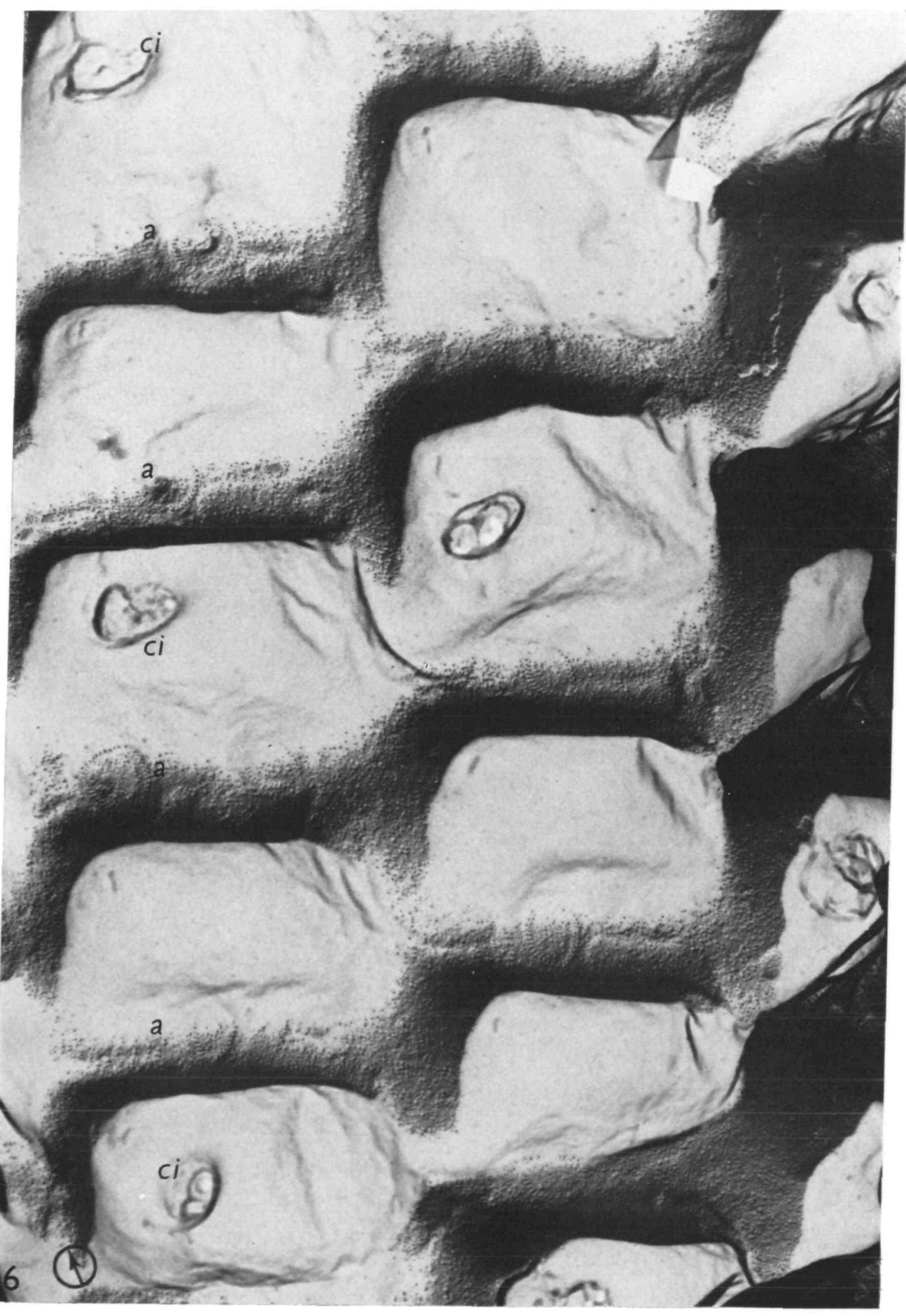


Fig. 7. Inside view of surface fracture, corresponding to Fig. 6 and the scheme of Fig. I. Longitudinal rows of square surface elements with the remnants of broken cilia $(c i)$ and parasomal sacs $(p s)$ in their elevated centre. Cilia are in line with attachment sites of trichocysts (arrows), represented by little craters and small patches of relatively large granules. The periods of the cilia-trichocyst lines are displaced to each other. Along the lines of trichocysts and cilia, conspicuous folds (solid double arrows) and occasionally perpendicular folds (dashed double arrow) are recognizable; they are considered to reflect impressions from the alveolar septa which were located underneath. $\times 32000$. 


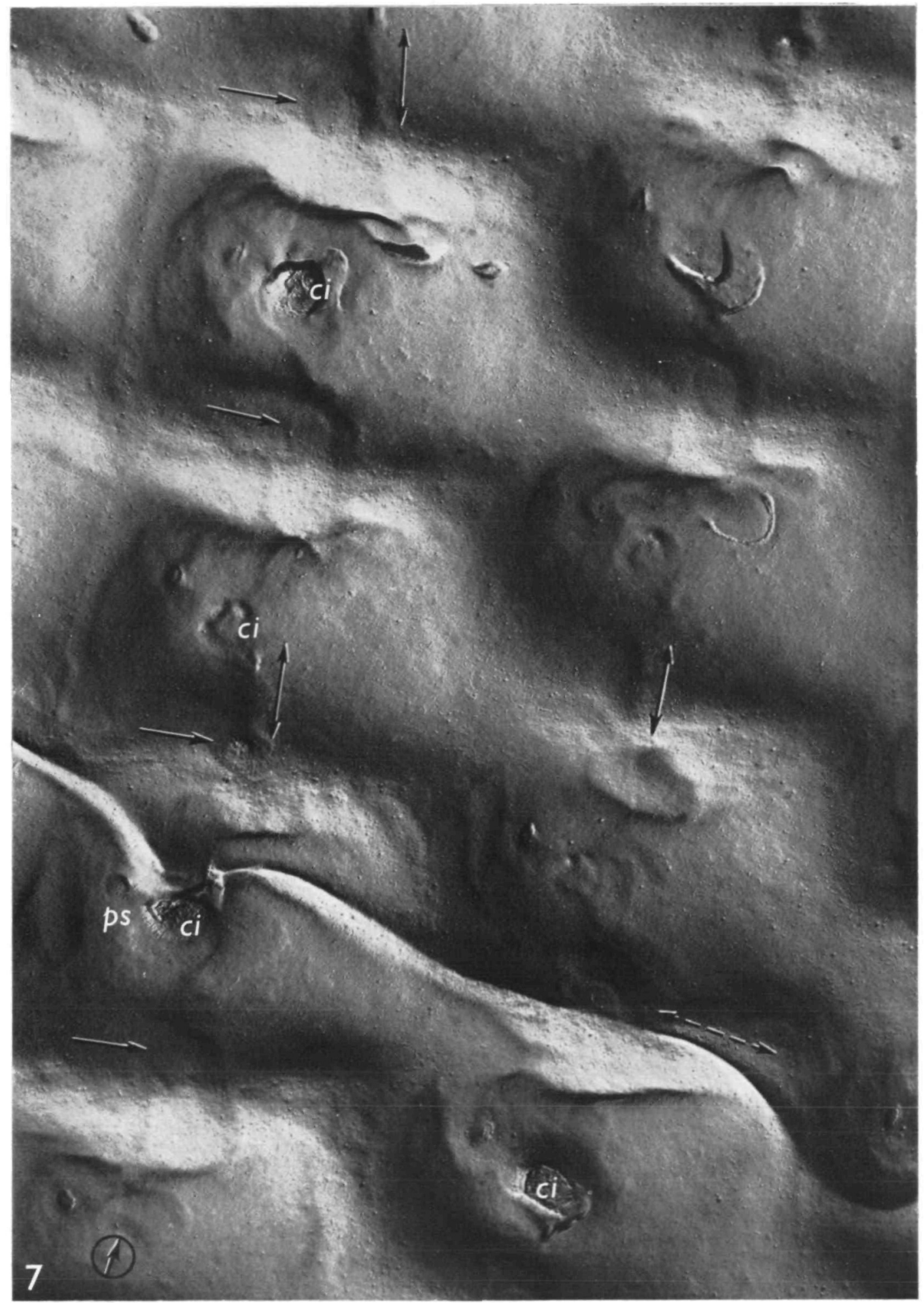


Figs. 8-1 3. Membrane specializations in regions containing trichocysts.

Fig. 8. Rings of granules of type $a$ and $b$ are found only on fracture faces and not on membrane surfaces exposed by decn etching. The ridge exposed by deep etching is considerably thicker than a split unit membrane would be. Incidentally a cleft is faintly visible along the middle line (arrows). The outside stratum represents the surface coat readily visible on ultrathin sections (see Fig. 17). $\times 60000$.

Figs. 9, ro. In addition to type $a$ - and $b$-rings, $c$-type membrane structures are present in the form of large granules or corresponding holes; they are seen on outside views only occasionally, apparently when part of the remaining plasmalemma was fractured away due to protrusion of the trichocyst tip. $\times 94000$.

Fig. II. Inside view of membrane specializations: $a$-type structures are faintly visible as holes and $c$-type granules as a centric patch of rather large granules. $\times 103000$.

Fig. I2. Grazing section through the attachment region of a trichocyst tip after fixation with $\mathrm{O}_{3} \mathrm{O}_{4}$ and potassium dichromate and block staining with uranyl acetate and phosphotungstic acid. The outlines of $a$-to $c$-type membrane substructures can be vaguely recognized (arrow). $\times 94000$.

Fig. I3. Spontaneous exocytosis of a trichocyst through the plasma membrane $(p m)$. The $a$-type ring $(a)$ remained unaltered. $\times 60000$. 

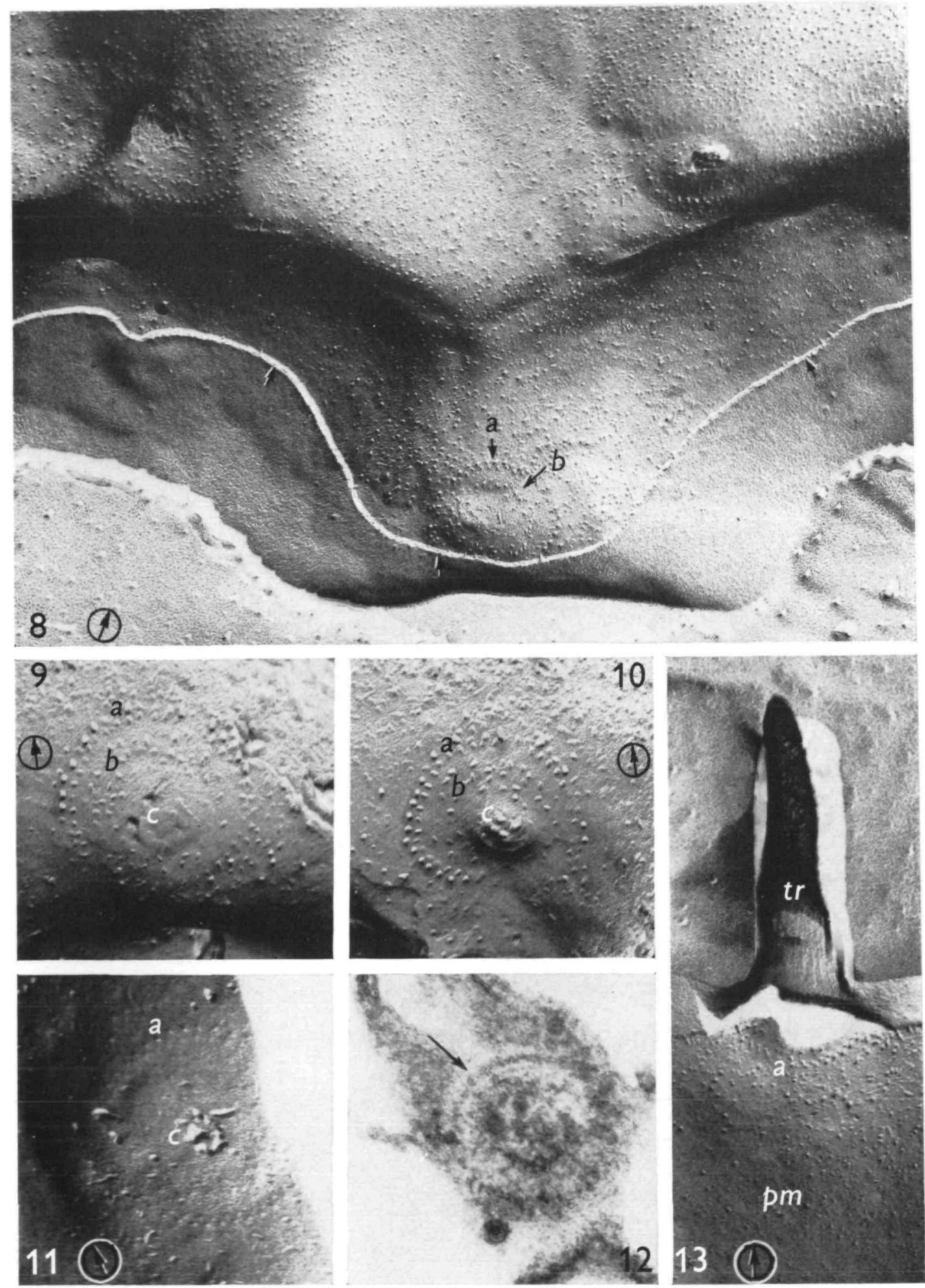
Figs. 14, 15. Perpendicular sections through cortex regions. Left: normal cell; right: after experimentally induced discharge of trichocysts.

Fig. I4. In untreated normal cells numerous trichocysts abutting to surface elevations alternate with cilia (ci) emerging from the troughs of the surface relief. Between trichocysts and cilia, alveoli $(a l)$ are located. $\times 10500$.

Fig. 15. Discharge of the majority of trichocysts was achieved by exposing cultures briefly to osmium tetroxide vapour. At $t r$, emptied trichocyst sacs are visible with their apical membrane closed after discharge. At $t r_{*}$ is an undischarged trichocyst. The ejection of the majority of trichocysts results in decay of the surface membrane complex, until the cytoplasm is covered only by the inner alveolar membrane $\left(a m_{i}\right)$. Even then, remnants of the other membranes, such as plasma membrane and outer alveolar membrane are seen to remain attached at regular intervals (arrows) at sites of trichocysta, cilia and alveolar septa. Evidently, after exocytosis the membranes were closed again. A similar partial disruption (without preceding ejection of trichocysts) could be obtained by exposing cells to a carbon dioxide atmosphere (see Figs. 19, 20). $\times 10500$. 


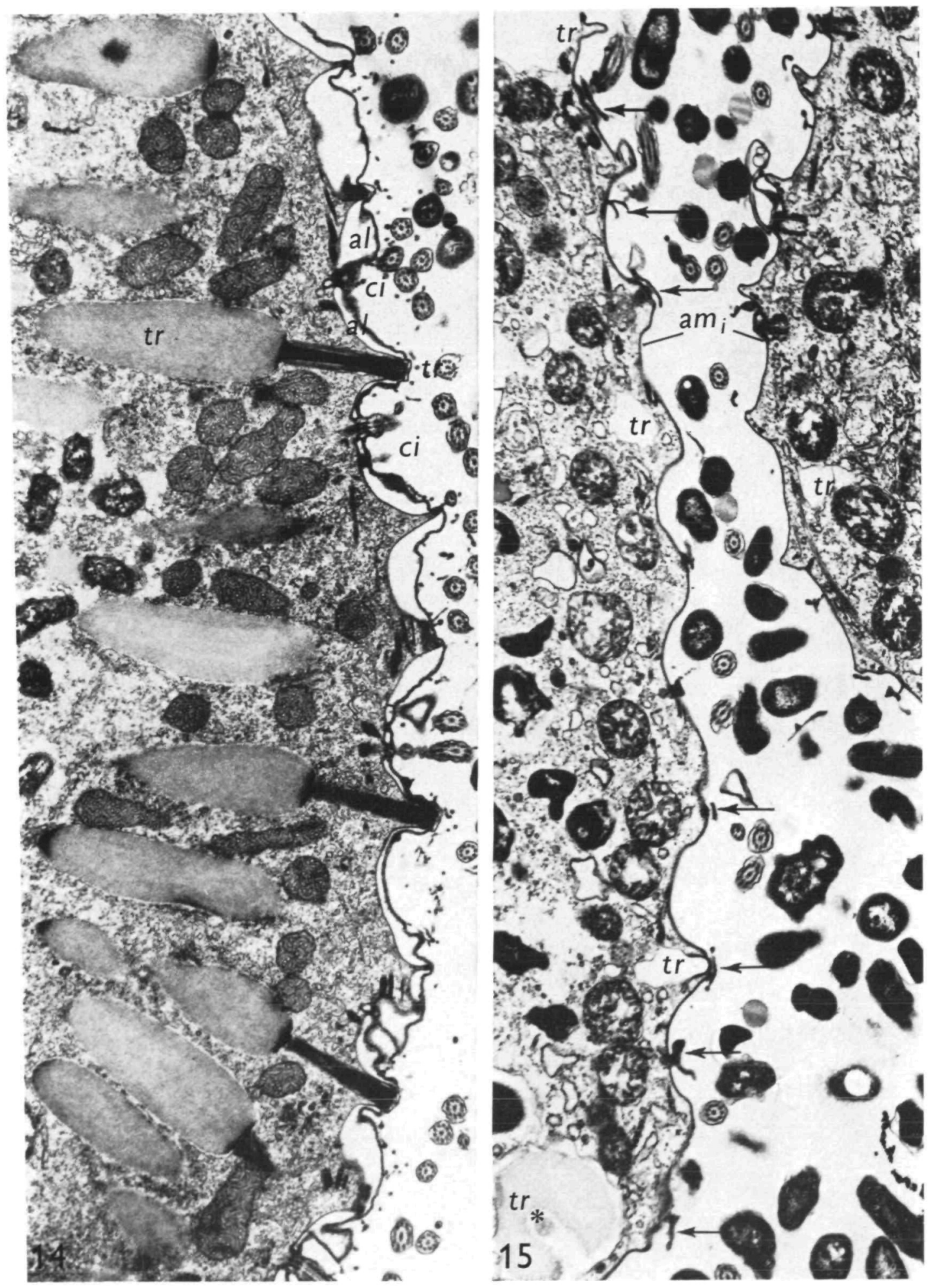


Figs. I6-20. Longitudinal sections through trichocysts. Figs. I6-I8, normal cells (Figs. 16, 17, fixed with $\mathrm{OsO}_{4}$-potassium dichromate; Fig. 18, negative contrasting of membranes by high concentration of acrolein and appropriate section staining). Figs. 19, 20, partial disruption of the surface membrane complex by a carbon dioxide atmosphere.

Figs. I6, I7. The trichocyst tip is covered by the trichocyst membrane $(\mathrm{tm})$ and the plasma membrane $(p m)$ and closely surrounded by the alveoli $(a l)$. Conspicuous electron-dense zones occur between the rims of alveolar membranes and the plasma membrane (large arrows), also between the trichocyst and the plasma membrane (small arrows). Note the occurrence of a rather thick coat on the outside of the plasmalemma. Fig. 16, ×60000; Fig. 17, × 126000.

Fig. 18. Negative contrast reveals a close attachment (encircled) of membranes on the trichocyst tip. $\times 58000$.

Figs. I9, 20. Exposing cells to carbon dioxide results in partial disruption of the cortical membrane complex without discharge of trichocysts. The regular occurrence of membrane fragments allows some conclusions on attachment sites $(a, b, e, g$; to be compared with Fig. 2) between individual membranes: $a$, the plasma membrane is connected with the outer alveolar membrane $\left(a m_{o}\right) ; b$, the plasmalemma is attached to the trichocyst membrane; $e$, the rims of the inner alveolar membrane $\left(a m_{i}\right)$ are fixed on the trichocyst membrane; $g$, the inner alveolar membranes are attached to each other along the alveolar septa. $\times 57000$. 


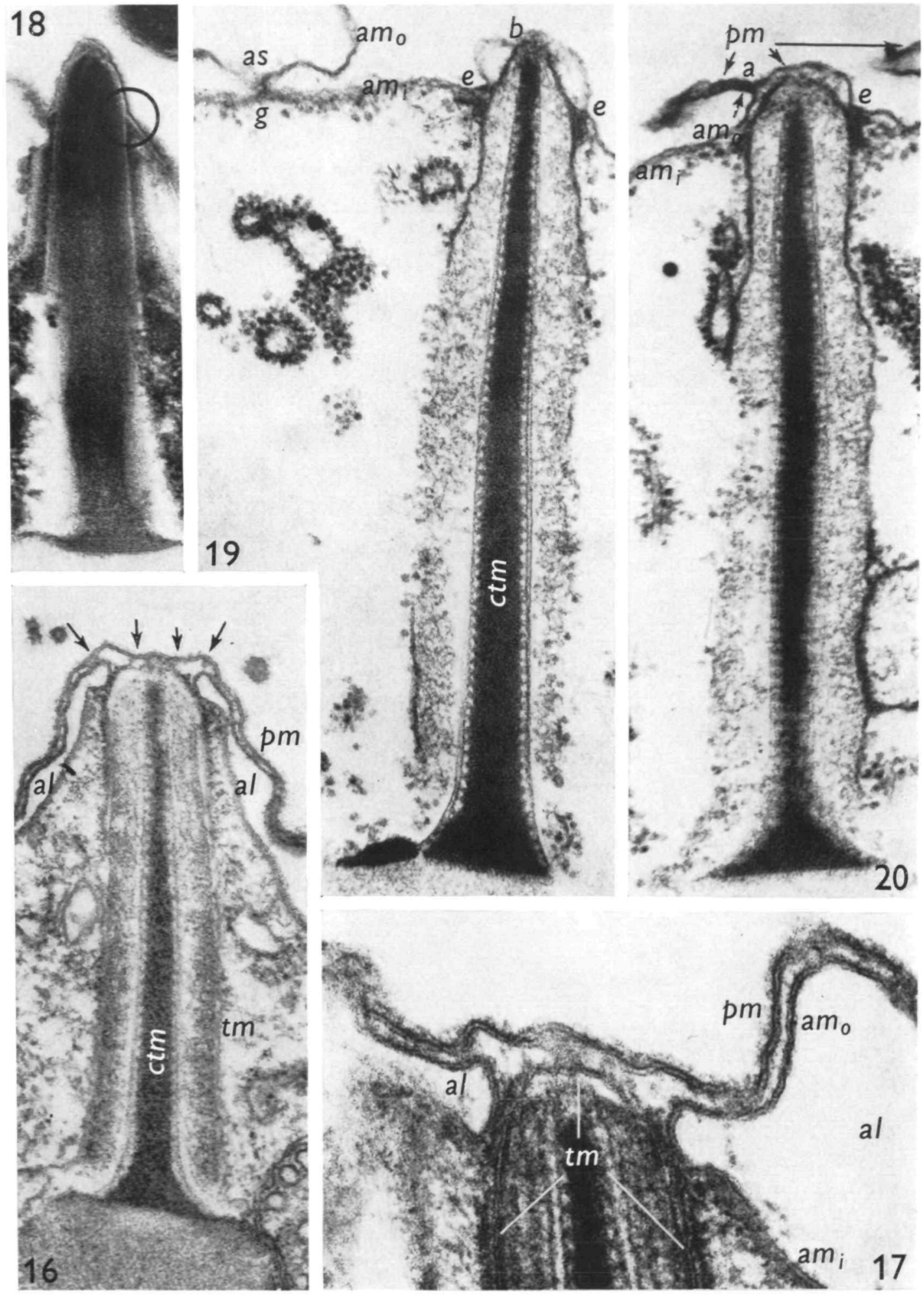


Fig. 21. Discharge of trichocysts can be triggered effectively by osmium tetroxide vapour as seen in this view from outside the cell. The situation corresponds to the ultrathin section of Fig. I5. The fracture exposes the granular inner alveolar membrane. Smooth circular membrane areas (arrows) possibly correspond to 'repaired' sites of discharged trichocysts. $\times 30000$.

Fig. 22. Discharge of single trichocysts was occasionally observed in normal cells. Plasma membrane $(p m)$ and trichocyst membrane $(\mathrm{tm})$ seem to fuse so that an opening is provided for the expulsion of the trichocyst. The alveoli remain unaffected. $\times 75000$. 


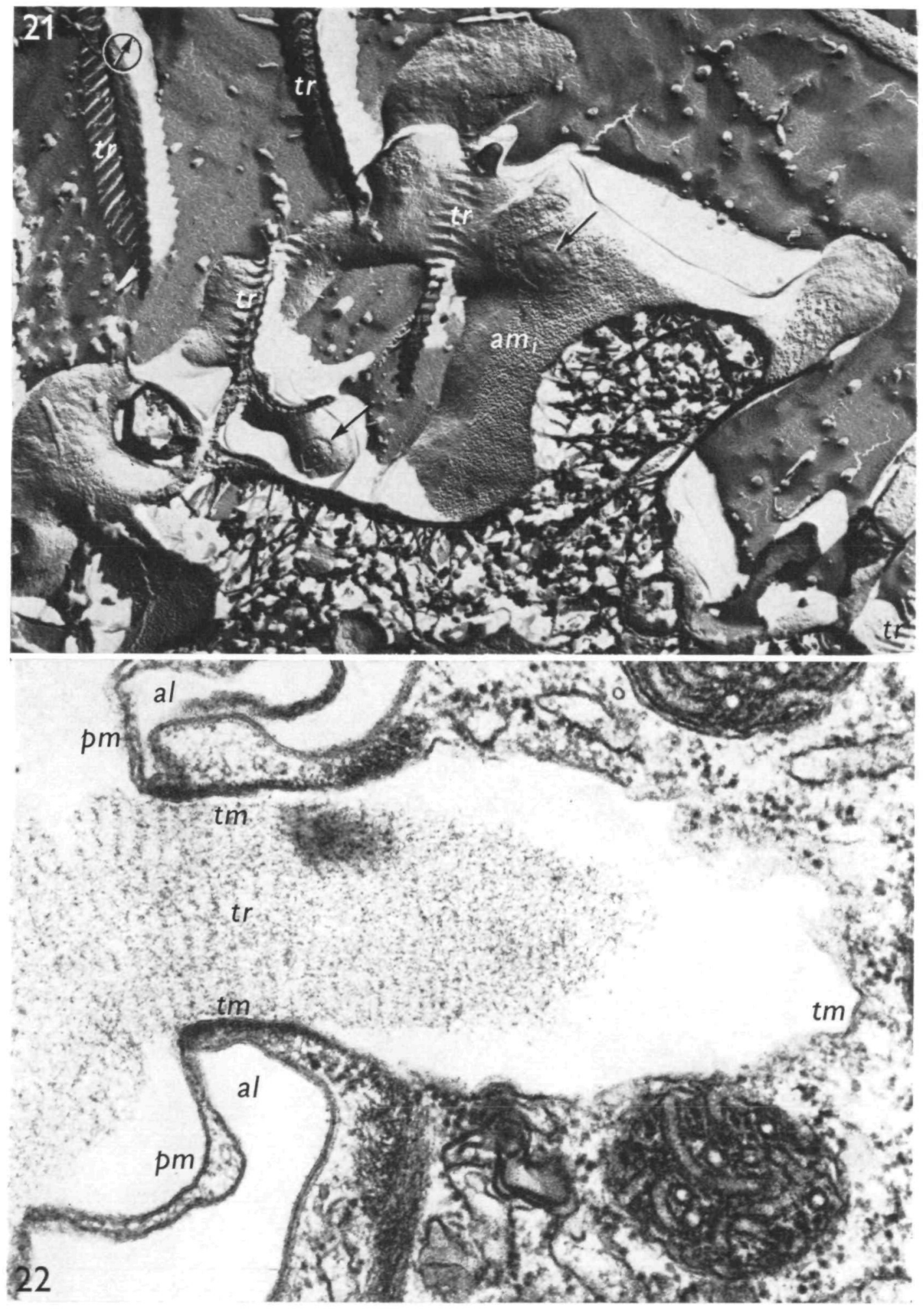


Fig. 23. Plasma membrane from outside, after experimentally induced discharge of trichocysts. The sites of the attachment zones of trichocysts present themselves in various aspects: the attachment sites between plasma membrane and alveolar membrane around the trichocysts ( $a$-type rings: $a_{1}-a_{7}$; dashed lattice) vary from almost complete to extremely fragmentary rings; occasionally large holes occur (arrows), but the plasmalemma was obviously 'repaired' at most exocytosis sites. The inner ( $b$ - and $c$-type) rings of membrane-bound granules (compare Figs. 2, 7, II) found in normal cells were no longer visible. The otherwise sinuate surface relief is rather flattened; this might be a consequence of disruption of the attachment sites between plasma membrane and alveolar membrane occurring. Around the fragments of cilia, rings of membrane-bound granules are still present. $\times 24000$. 


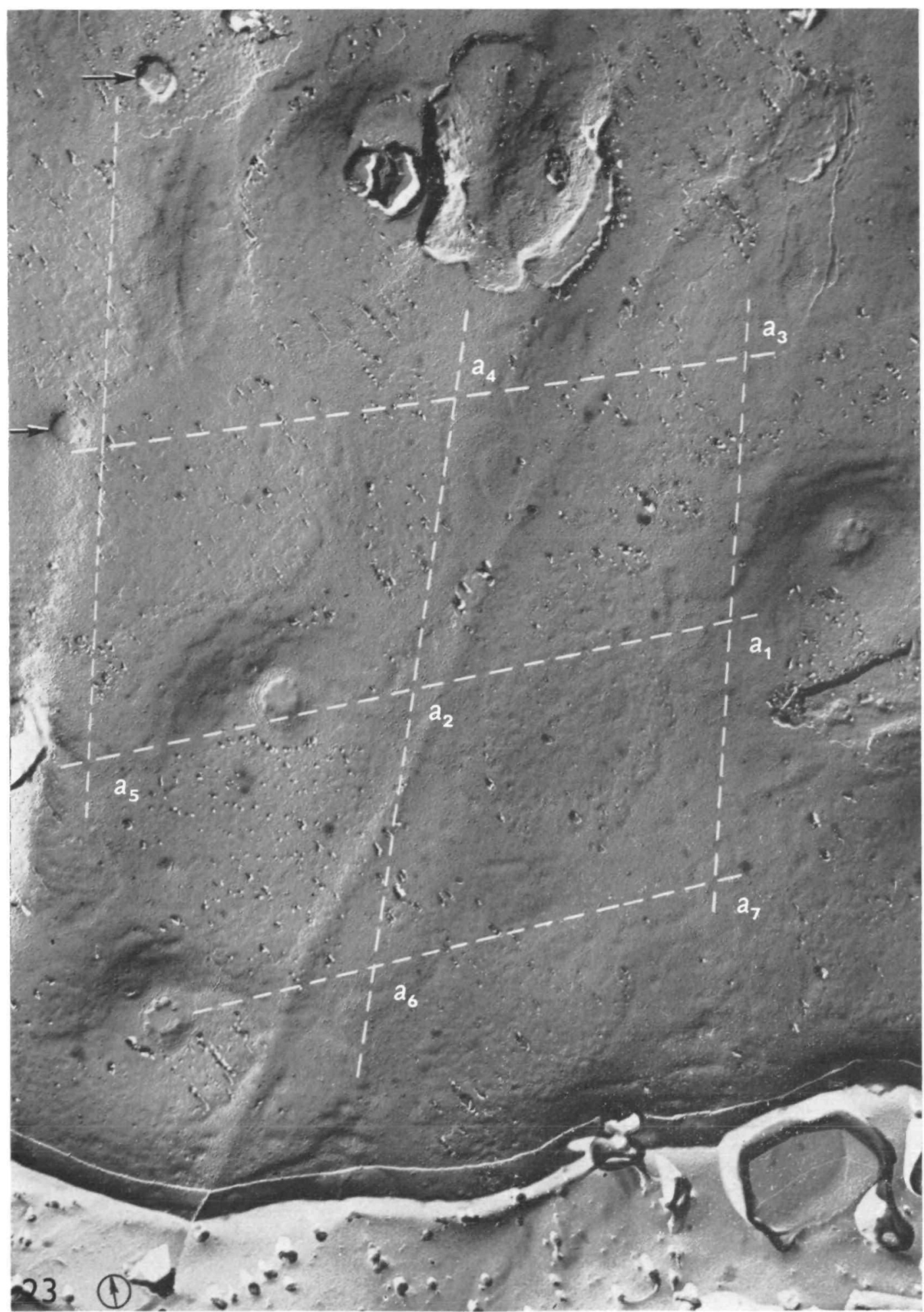


Fig. 24. Inside view of the plasma membrane after experimentally induced discharge of trichocysts. Regions where the cilia penetrate the plasmalemma are characterized by diffuse rings of granules and parasomal sacs ( $p s)$ in close vicinity. Though the surface relief of the cell body became rather smooth, the original position of longitudinal elevations can be localized by fragments of cilia and the occasional preservation of a few trichocyst attachments (arrows). However, at most sites where trichocysts would be expected in normal cells (dashed lattice), no regular arrangements of granules can now be recognized. $\times 29000$. 


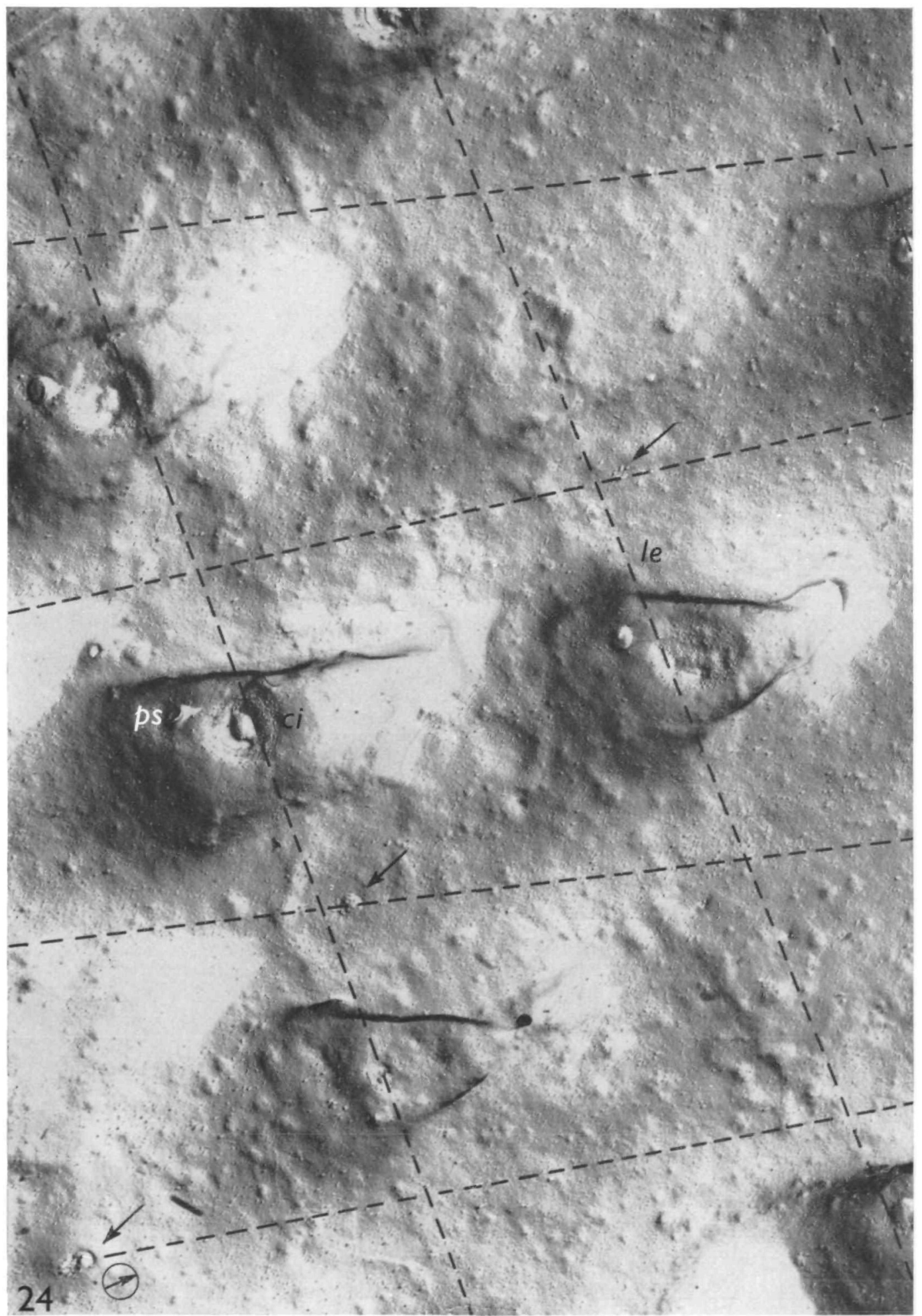


